\title{
Effects of oolitic haematite ore additions on the compressive strength of iron ore pellets
}

\author{
by F. Yang, S.P. Zhang, T. Tang, and Sh.Y. Hu
}

\section{Synopsis}

The effects of oolitic haematite ore additions on the compressive strength of iron ore pellets were investigated in a preliminary study. It was found that additions of oolitic haematite at levels of up to $15 \%$ by mass decreased the compressive strength from about $3250 \mathrm{~N}$ to $1729.1 \mathrm{~N}$, which is below the minimum requirement of $2500 \mathrm{~N}$ for use in a blast furnace. As the oolitic haematite content increases, the $\mathrm{Fe}_{2} \mathrm{O}_{3}$ recrystallizes, forming frangible, unevenly distributed crystallites that are incompletely interlinked, thus reducing the compressive strength of the pellets. At the same time, as the oolitic haematite content is increased from zero to $15 \%$, the porosity of the pellets increases from $13.11 \%$ to $19.85 \%$, again resulting in a decrease in strength. It was found that the maximum amount of oolitic haematite should be $10 \%$ in order for the pellets to be suitable for blast furnace feed.

Keywords

iron ore, pelletization, oolitic haematite ore, compressive strength.

\section{Introduction}

In recent years, the rapid development of China's iron and steel industry has led to an increasing shortage of domestic iron ore resources. China currently imports more than $60 \%$ of its iron ore requirements (Xu and Shi, 2015). In order to reduce dependence on foreign iron ore resources, it is necessary to increase the development and utilization of existing iron ore resources in China. Oolitic haematite ore is widely distributed and available in China. The explored reserves of this type of iron ore reach $3720 \mathrm{Mt}$, which is approximately $11 \%$ of the total iron ore resources (Sun, Han, and Gao, 2014). Oolitic haematite ore has a unique structure, as shown in Figure 1, characterized by spherical grains composed of concentric layers. The iron oxides, fluorapatite, and chamosite (a hydrous aluminium silicate of iron) are intimately intermixed; moreover, microfine-grained haematite is disseminated with gangue minerals (Wu, Wen, and Cen, 2011). It is difficult to obtain high-grade iron concentrates with a low phosphorus content using conventional magnetic separation or froth flotation methods following fine grinding of oolitic haematite ores (Li et al., 2013; Nunes et al., 2012; Yu, Yu, and Xu, 2013). However, it is very important for the future of China's steel industry to increase the exploitation and utilization of this kind of ore.

Oolitic haematite ores vary widely in chemical composition. Oolitic haematite is one of the most refractory iron ores, and is characterized by low total iron content (30-55\%, although the grade in individual places can reach more than $55 \%$ ), and high phosphorus (0.4-1.8\%) and alumina ( 2.5-9.0\%) contents. After beneficiation, the ore grade is about $58 \%$, the $\mathrm{SiO}_{2}$ content is above $9 \%$, and the contents of $\mathrm{Al}_{2} \mathrm{O}_{3}$ and $\mathrm{P}$ are higher $\left(0.4 \%-1.8 \% \mathrm{P}\right.$ and $2.5 \%-9.0 \% \mathrm{Al}_{2} \mathrm{O}_{3}$, respectively). Increasing the concentrate grade to more than $64 \%$ Fe will not only incur a great increase in mineral processing costs, but the metal yield will also decrease. In this study in order to explore the possibility of utilizing oolitic haematite with a higher grade of iron, which has not been enriched by mineral processing, oolitic haematite ore was used as an addition in pellet production, and a preliminary study of the effect of various additions on the compressive strength of pellets was carried out, based on the changes in the porosity of the finished pellets and the oxidation-recrystallization of the pellets,. The results can provide a theoretical basis and technical guidance for the industrial development and utilization of this kind of iron ore.

\section{Experimental methods}

\section{Pellet preparation}

The raw materials used to prepare pellets were

* Hubei Key Laboratory for Efficient Utilization and Agglomeration of Metallurgical Mineral Resources, School of Resource and Environmental Engineering, Wuhan University of Science and Technology, China.

(C) The Southern African Institute of Mining and Metallurgy, 2018. ISSN 2225-6253. Paper received Mar. 2018; revised paper received Apr. 2018. 


\section{Effects of oolitic haematite ore additions on the compressive strength of iron ore pellets}

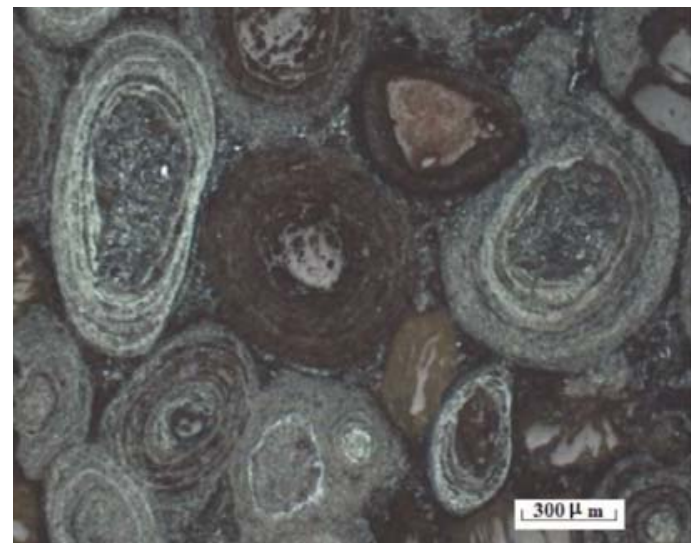

Figure 1-Microstructure of typical oolitic haematite

magnetite concentrate and bentonite from an iron and steel plant, and oolitic haematite ore from Enshi in western Hubai Province, China. The chemical compositions are listed in Table I. As indicated in Table I, the grade of iron in the oolitic haematite ore is lower than that of the magnetite concentrate, and the impuritiy contents are higher.

To investigate the effects of the oolitic haematite on the compressive strength of the pellets, additions of $5 \%, 10 \%$, and $15 \%$ by mass were made to the raw materials mix. Pellets without any oolitic haematite were also prepared as a baseline standard. The bentonite content was $2.0 \%$ in all cases. The proportions of raw materials are shown in Table II.

Green pellets were prepared in a disc pelletizer of $1.0 \mathrm{~m}$ diameter and $0.2 \mathrm{~m}$ rim depth, rotating at $20 \mathrm{r} / \mathrm{min}$ and inclined at $45^{\circ}$ to the horizontal. The pelletizing time was 30 minutes. The moisture content of the green pellets was about $8 \%$. The green pellets were screened to separate the $8-16 \mathrm{~mm}$ size fraction, and dried at $150^{\circ} \mathrm{C}$ for 2 hours in a drying cabinet. The dried green pellets were placed into a muffle furnace preheated to $900^{\circ} \mathrm{C}$ and with an air flow rate of $1.5 \mathrm{~L} / \mathrm{min}$. The furnace was then heated to $1250^{\circ} \mathrm{C}$ over a period of 30 minutes, and the pellets were roasted at $1250^{\circ} \mathrm{C}$ for 20 minutes, then cooled to ambient temperature.

\section{Testing of pellet properties}

The compressive strength of finished pellets was tested using a universal test machine (UTM) according to chinese standard GB/T14201-1993. The pressurizing capacity of the device must be greater than $10 \mathrm{kN}$, and the transmission capacity of the load cell greater than $10 \mathrm{kN}$. The running speed of the head is $15 \pm 1 \mathrm{~mm} / \mathrm{min}$, which necessitates constant speed pressurizing. The pellet specimen was placed between two horizontal disks and then slowly pressed by the motor-driven UTM until it developed cracks and eventually collapsed. The load cell on the bottom disk recorded the compressive load versus displacement data. Twelve sample pellets of each pellet recipe were tested; the maximum and the minimum values were deleted, and the average of the rest of the values was considered to be the final compressive strength of the finished pellets. The porosities of the finished pellets were tested by the mercury injection method. The finished pellets were also characterized under a mineralogical microscope.

\section{Experimental results and analysis}

\section{Results}

The effects of oolitic haematite ore on the compressive strength of the pellets are shown in Figure 2. As the oolitic haematite addition is increased from zero to $15 \%$, the compressive strength of the pellets gradually decreases, from about $3250 \mathrm{~N}$ with no oolitic haematite addition to $1729.1 \mathrm{~N}$ with $15 \%$ addition.

Figure 3 shows that the porosity of finished pellets increases from $13.11 \%$ to $19.85 \%$ as the proportion of oolitic haematite ore increases from zero to $15 \%$. The microstructures of the pellets are shown in Figure 4

\section{Analysis}

As can be seen from Figure 2, the compressive strength of the pellets decreases continuously with increasing

\begin{tabular}{|c|c|c|c|c|c|c|c|}
\hline \multicolumn{8}{|c|}{$\begin{array}{l}\text { Table I } \\
\text { Chemical composition of pelletizing materials } \\
\text { (mass \%) }\end{array}$} \\
\hline Raw materials & Total Fe & $\mathrm{FeO}$ & $\mathrm{SiO}_{2}$ & $\mathrm{CaO}$ & MgO & $\mathrm{Al}_{2} \mathrm{O}_{3}$ & $\mathbf{P}$ \\
\hline $\begin{array}{l}\text { Magnetite } \\
\text { concentrate }\end{array}$ & 67.84 & 18.40 & 2.39 & 0.025 & 0.016 & 0.28 & 0.03 \\
\hline $\begin{array}{l}\text { Oolitic } \\
\text { haematite ore }\end{array}$ & 58.18 & 1.97 & 9.31 & 0.02 & 0.26 & 4.20 & 0.86 \\
\hline Bentonite & 1.67 & - & 57.44 & 2.51 & 2.40 & 11.20 & 0.03 \\
\hline
\end{tabular}

Table II

Proportions of raw materials in pelletizing mix (mass \%)

\begin{tabular}{|l|c|c|}
\hline Oolitic haematite ore & Magnetite concentrate & Bentonite \\
\hline 0 & 98.0 & 2.0 \\
5.0 & 93.0 & 2.0 \\
10.0 & 88.0 & 2.0 \\
15.0 & 83.0 & 2.0 \\
\hline
\end{tabular}

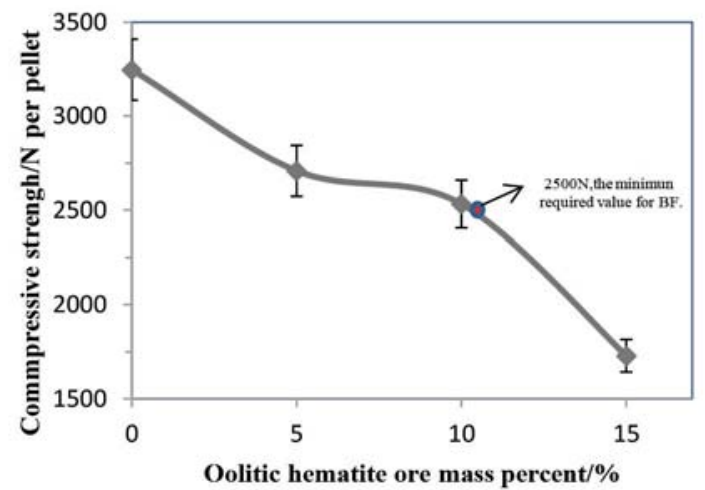

Figure 2-Effects of oolitic haematite ore on the compressive strength of pellets 


\section{Effects of oolitic haematite ore additions on the compressive strength of iron ore pellets}

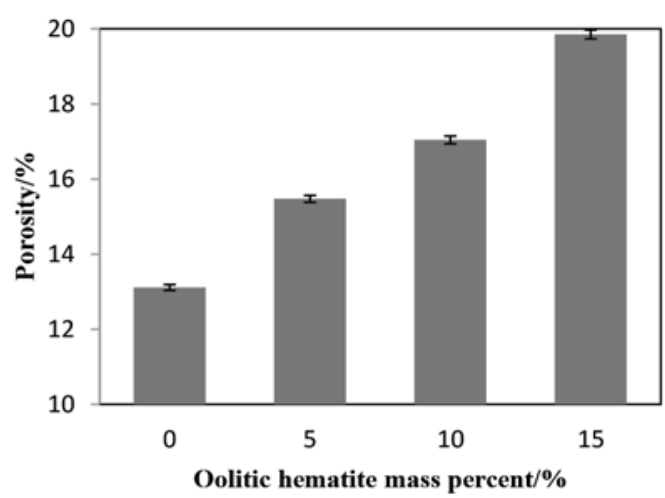

Figure 3-Porosity of the pellets with different proportions of oolitic haematite ore

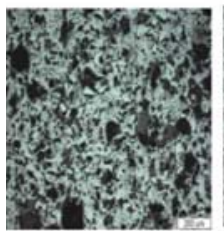

(a)

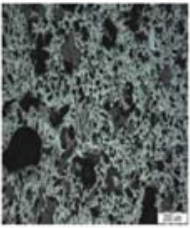

(b)



(c)

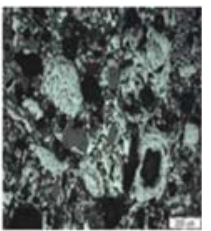

(d)
Figure 4-Microstructures of pellets with different proportions of oolitic haematite ore

proportions of oolitic haematite ore. As the oolitic haematite addition increases from zero to $10 \%$, the compressive strength of the pellets decreases from $3247.2 \mathrm{~N}$ to $2532.6 \mathrm{~N}$, which still meets the requirement for blast furnace feed. However, at $15 \%$ addition, the compressive strength falls to $1729.1 \mathrm{~N}$, which is below the requirements of the modern large-scale blast furnace.

The porosity of pellets has a significant effect on the compressive strength. According to the Griffith microcrack theory, the relationship between the critical rupture stress and the elastic modular ratio (i.e., the ratio of normal stress to the corresponding normal strain) can be expressed as Equation [1] (Shen et al., 2014; Gao et al., 2013a, 2013b):

$$
\sigma=Y \sqrt{ }(E \gamma / C)
$$

where $\sigma$ is the critical rupture stress $(\mathrm{MPa}), Y$ is a correlation coefficient that is determined by the size and shape of the sample and its crack (dimensionless), $E$ is the elastic modular ratio $(\mathrm{GPa}), \gamma$ is the surface energy $(\mathrm{J})$, and $C$ is the halflength of the crack $(\mathrm{m})$.

The empirical formula expressing the relationship between the elastic modular ratio and the porosity is shown in Equation [2)] (Bao and Jin, 2010; Gao et al., 2013c):

$$
E / E_{0}=1-K_{1} \varepsilon+K_{2} \varepsilon^{2}
$$

where $E_{0}$ is the elastic modulus ratio of a sample without any pores (GPa), $K_{1}$ and $K_{1}$ are constants determined by the shape and direction of the cracks (dimensionless), and $\varepsilon$ is the porosity. The last term in Equation [2], $K_{2} \varepsilon^{2}$. is relatively small and can thus be ignored.

Equations [1] and [2] show that the critical rupture stress $\sigma$ decreases when the porosity $\varepsilon$ of the pellet increases, and the compressive strength of the pellet will consequently be diminished. Therefore, an increase in the proportion of oolitic haematite ore may result in an increase in the porosity of the pellets and subsequently in a decrease in compressive strength of the finished pellets.

As can be seen from Figure $4 \mathrm{a}$, with no addition of oolitic haematite the oxidation and recrystallization of $\mathrm{Fe}_{3} \mathrm{O}_{4}$ is better, and the crystallite is connecting together compactly and is evenly distributed. The crystallite is interlinkcrystallite. It is known that $\mathrm{Fe}_{3} \mathrm{O}_{4}$ is oxidized to $\mathrm{Fe}_{2} \mathrm{O}_{3}$ and that $\mathrm{Fe}_{2} \mathrm{O}_{3}$ recrystallization is the main bonding mechanism for pellets. The better the recrystallization of $\mathrm{Fe}_{2} \mathrm{O}_{3}$, therefore, the greater the strength of the pellets, thus the compressive strength of the pellets without oolitic haematite ore is the greatest. An increase in the proportion of oolitic haematite ore results in an increase in the $\mathrm{Fe}_{2} \mathrm{O}_{3}$ content of the pellets and thus a decrease in the degree of $\mathrm{Fe}_{3} \mathrm{O}_{4}$ oxidation and recrystallization as $\mathrm{Fe}_{2} \mathrm{O}_{3}$. In this case, the $\mathrm{Fe}_{2} \mathrm{O}_{3}$ crystallites are frangible and unevenly distributed, which leads to crystallite interlinkages- developing incompletely and a deterioration in the compressive strength of the finished pellets, as shown in Figure 4d. This is another reason for the decrease in the pellets' strength.

\section{Conclusions}

The compressive strength of magnetite concentrate pellets with different proportions of oolitic haematite ore was investigated. The porosity of finished pellets was determined to clarify how oolitic haematite ore affects the compressive strength. The main findings are summarized as follows.

> The compressive strength of pellets decreases gradually with increasing mass fraction of oolitic haematite ore from zero to $15 \%$. At mass fractions of oolitic haematite ore more than $10 \%$, the compressive strength of pellets is lower than $2500 \mathrm{~N}$. Therefore, the proportion of oolitic haematite ore in pellets should not exceed $10 \%$.

> The porosity of finished pellets increases gradually with increasing mass fraction of oolitic haematite ore. As the content of oolitic haematite ore increases from zero to $15 \%$, the porosity of pellets increases from $13.11 \%$ to $19.85 \%$. The increase of porosity leads to a decrease in the compressive strength of pellets.

> With increasing oolitic haematite content, the degree of $\mathrm{Fe}_{3} \mathrm{O}_{4}$ oxidation and recrystallization as $\mathrm{Fe}_{2} \mathrm{O}_{3}$ decreases; the recrystallized grains are poorly interconnected and unevenly distributed, which again decreases the consolidation and strength of oxide pellets.

\section{Acknowledgements}

The authors greatly appreciate the support of the Science and Technology Research Project of Hubei Provincial Department of Education. (no. B2017002).

\section{References}

BAo, Y. and Jin, Z. 2010. Size effects and a mean strength criterion for ceramics. Fatigue and Fracture of Engineering Materials and Structures, vol. 16 , no. 8. pp. 829-835. 
GAO, Q.J., WEI, G., HE, Y.B., and SHEN, F.-M. 2013a. Effect of MgO on compressive strength of pellet. Journal of Northeastern University, vol. 34, no. 1. pp. 103-106.

GAo, Q.J., JiAnG, X., WeI, G., and Shen, F.-M. 2013b. Characterization of consolidation degree of iron ore pellet by mercury injection method. Journal of Northeastern University, vol. 34, no. 6. pp. 832-835.

Gao, Q.J., Guo, W., Jiang, X., Du, G., Wei, G., and Fengman, S. 2013c. Effect of boron sludge on strength of pellet. Journal of Materials and Metallurgy, vol. 12, no. 1. pp. 2-3.

LI, G., Zhang, S., RAo, M., Zhang, Y., and JiAng, T. 2013. Effects of sodium salts on reduction roasting and Fe-P separation of high-phosphorus oolitic hematite ore. International Journal of Mineral Processing, vol. 124, no. 22. pp. 26-34.

Nunes, A.P.L., Pinto, C.L.L., ValadÃo, G.E.S., and de MagalhãesViana, P.R. 2012. Floatability studies of wavellite and preliminary results on phosphorus removal from a Brazilian iron ore by froth flotation. Minerals Engineering, vol. 39, no. 12. pp. 206-212.
SHEn, F.M., GAO, Q.J., Xin, J., WeI, G., and ZHENG, H.-Y. 2014. Effect of magnesia on the compressive strength of pellets. International Journal of Minerals, Metallurgy and Materials, vol. 21, no. 5. pp. 431-437.

Sun, Y.S., Han, Y.X., and Gao. P. 2014. Distribution behavior of phosphorus in the coal-based reduction of high-phosphorus-content oolitic iron ore. International Journal of Minerals, Metallurgy and Materials, vol. 21, no. 4. pp. 331-338.

Wu, J., Wen, Z., and CEN, M. 2011. Development of technologies for high phosphorus oolitic hematite utilization. Steel Research International, vol. 82, no. 5. pp. 494-500.

Xu, H.J. and SHI, X.F. 2015. Experiment of coal-based direct reduction of high phosphorus oolitic hematite. Journal of Iron and Steel Research, vol. 27, no. 12. pp. 30-35

Yu, K.P., Yu, Y.F., and Xu, X.Y. 2013. Separation behavior and mechanism of hematite and collophane in the presence of collector RFP-138. Transactions of Nonferrous Metals Society of China, vo. 23, no. 2. pp. 501-507.

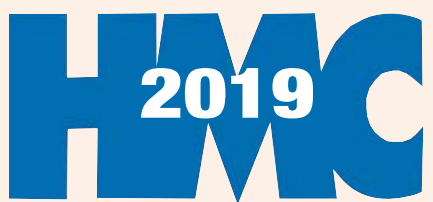

HEAVY MINERALS 2019



The Southern African Institute of Mining and Metallurgy

in collaboration with The Zululand Branch are organising

The Eleventh International

HEAVY MINERALS CONFERENCE

'Renewed focus on Process and Optimization'

5-6 August 2019-Conference

7 August 2019-Technical Visit

Cape Winelands, Western Cape

\section{CONFERENCE THEME}

The series of heavy minerals conferences has traditionally focused on the industries associated with ilmenite, rutile and zircon. There are many other economic minerals which have specific gravities such that they may also be classed as 'heavy minerals'. The physical and chemical properties of these other minerals results in them being processed by similar technologies and sharing similar markets to the more traditional heavy minerals. In this conference we focus on optimization of processes/mining and recovery improvements
Contact: Yolanda Ndimande

Conference Co-ordinator - Tel: +27 11 834-1273/7

Fax: +27 $11833-8156$ or +27 11 838-5923

E-mail: yolanda@saimm.co.za

Website: http://www.saimm.co.za

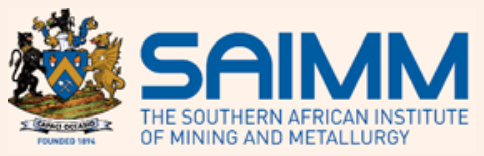

\section{First Announcement and Call for Papers}

